Article

\title{
A Kitchen with too Many Cooks: Factors Associated with Hospital Profitability
}

\author{
Na-Eun Cho and KiHoon Hong * \\ College of Business, Hongik University, Seoul 04066, Korea; ncho@hongik.ac.kr \\ * Correspondence: khhong@hongik.ac.kr; Tel.: +82-2-320-1757
}

Received: 4 January 2018; Accepted: 25 January 2018; Published: 26 January 2018

\begin{abstract}
In this paper, we carefully investigate previous literature to extract 10 relevant factors to explain the hospital profitability and build an econometrically well-specified model of explaining hospital profitability that does not suffer from omitted variable bias. Then we provide empirical evidence to a common belief that the objective function of a hospital varies with the type of hospital. We identified distinct objective functions for three types of hospitals: for-profit hospitals are driven by the overarching agreed-upon goal of profit maximization for shareholders; government hospitals, which are often the insurers of last resort, are obliged to put the public interest over profit objectives; nonprofit hospitals, which are legally prohibited from distributing profits, occupy the middle ground between for-profit and government hospitals. The results of this paper suggest that the ownership type should determine the factors on which hospitals focus and hence are useful to hospital management and academic researchers.
\end{abstract}

Keywords: hospital; profitability; ownership; nonprofit

\section{Introduction}

The financial viability of hospitals is a key determinant of sustainability in the healthcare system, as it ultimately affects the costs, quality, and accessibility of care provided to patients. With its importance, many scholars have examined several financial outcomes of hospitals such as revenue, efficiency, and profitability over the last several decades [1-20]. For instance, they have found that hospital efficiency is determined by several factors such as scope of service, occupancy, ownership, and information technology. $[5,11,12,14,17]$. Additionally, many existing studies discuss the individual relevant factors of profitability at various levels such as organizational, managerial, patient, and market levels [1-9,13,14,16-21].

However, careful investigation of past literature on hospital profitability, that is, the most common measure for hospital performance, reveals the lack of a well-specified factor model that explains how hospitals become profitable. To fill this gap, we reckon that a well-specified econometric model to explain hospital profitability can be achieved by extracting and testing all relevant factors discussed in previous literature. Hence, in this paper, we carefully and extensively investigate previous literature to extract several relevant factors to explain the hospital profitability.

The purpose of our study is not only to empirically test the effects of the determinants to the hospital profitability, but also to provide empirical evidence to a common belief that the objective function of a hospital varies with the type of hospital. Much of the existing literature that investigates the determinants of hospital profitability has overlooked that managerial goals can differ across organizations. Hospital ownership type has previously been used only as a control variable, but we use it to examine the variation in the effects of the determinants of profitability. We identified distinct objective functions for three types of hospitals: for-profit hospitals are driven by the overarching agreed-upon goal of profit maximization for shareholders; government hospitals, which are often the 
insurers of last resort, are obliged to put the public interest over profit objectives; nonprofit hospitals, which is legally prohibited from distributing profits, occupy the middle ground between for-profit and government hospitals. Our study presumes that the effects of the determinants of profitability vary with the objective functions associated with the respective types of hospital ownership.

To achieve these goals, we first employed a well-specified multiple regression analysis with 10 independent variables to the entire sample. With all sample hospitals, we found that only 3 out of 10 estimated coefficients are consistent to the ex ante expectation, provided by the previous literature. Puzzled by the contradicting result, we conducted further investigation by dividing the sample hospitals into three sub-groups: for-profit, nonprofit, and government. This further analysis reveals that most of the signs of the estimated coefficients are most consistent to the ex ante expectation for for-profit hospitals and least consistent for nonprofit hospitals.

Investigating the determinants of hospital profitability and their impacts can enhance our understanding of the hospital industry. Further investigation of the varying relationship between the hospital operating factors and their profitability depending on hospital ownership types reveals that nonprofit hospitals behave very distinctively. This result confirms the generally believed hypothesis that nonprofit hospitals do not have a clearly defined managerial objective due to their unique ownership structure [22,23]. As Hansmann (1996) points out, it is well accepted that nonprofit hospitals generally do not have controlling owners who can provide clear and direct guidance to the hospital management [22]. Too many cooks can indeed confuse the master chef and spoil the broth.

Our study makes several contributions to practice and research. For research, this study, to the best of our knowledge, is the first attempt to construct how the effects of the determinants to the hospital profitability vary with the type of ownership. Furthermore, our results suggest that research on the group heterogeneity among nonprofit organizations warrants immediate attention. Specifically, we believe that the results of the current paper paved the road for further investigation of perhaps inefficient or inconsistent management of some hospitals and thereby shed some light on sustainability of the hospital industry. For practice, our results provide guidance to hospital administrators on formulating strategies that favorably affect performance. Specifically, our study suggests that the ownership type should determine the factors on which hospitals focus.

The paper is organized as follows. In Section 2, we describe the research background and develop hypotheses. Section 3 presents the model, and Section 4 presents our empirical results. Section 5 provides the conclusion. Because of the extensive notation in the paper, a glossary is provided.

\section{Research Background and Hypotheses Development}

\subsection{Literature Review}

Previous studies have investigated the determinants of hospital profitability at the (1) organizational (e.g., teaching status, hospital size, ownership, system status), (2) managerial (e.g., age of plant, debt utilization, service index, labor intensity), (3) patient (e.g., Medicaid mix, Medicare mix, uncompensated care mix), and (4) market levels (e.g., physician density, patient income, hospital concentration) $[1-9,13,14,16-21]$. Some studies focus on a few individual relevant factors such as bed size, ownership, or system affiliation [1-5,14,18-20], while others provide more comprehensive picture of drivers of hospital profitability $[6,7,9,13,16,17,21]$. These studies have implications for policy making and practice relevant for improving the financial viability of hospitals.

The extant studies on the determinants of hospital profitability, however, have yielded mixed results. System affiliation, for example, was not associated with improved profitability in one study $[2,6]$ but was a major determinant of profitability in others [4,21]. Additionally, teaching status had a positive effect on profitability in one study [13], while having a negative effect in another [17]. These results can reflect the differences in sample period, size, and other hospital characteristics.

To address this issue, we argue in this study that the effects of the determinants of hospital profitability would vary with ownership categories. Ownership, which can be defined as "the right 
to control the firm and [ ... ] to appropriate the firm's residual earnings" ([22] p. 11), can vary with ownership dispersion (concentrated and dispersed), the identity of stakeholders (consumers, producers, and risk bearers), and organizational goals (for-profit, government, and not-for-profit). Previous literature has suggested that organizations with different ownership employ different kinds of incentives, auditing, control systems, etc. [24,25], which ultimately affect a wide range of managerial actions.

That said, there are mainly three types of ownership in the hospital industry: for-profit, government, and nonprofit. These hospitals have different organizational goals, which provide guidelines or constraints associated with decision-making [26,27]. For-profit ownership has the clear organizational goal of maximizing profits for shareholders. Government ownership implies adherence to policies established by legislative enactment or executive order [28,29], which oblige the organization to serve the public interest to the best of its ability while making the most economical use of resources. Nonprofit ownership provides socially desirable goods or services, the delivery of which is funded by the recipient constituencies or donors. Despite the clear distinction among three types of hospitals, there are very limited studies to date on how the relationship between the operating factors and profitability depends on hospital ownership types, or they found no significant effect of ownership type $[1,3,5,8,9]$. In most cases, the variable of ownership type has been included as one of the independent or control variables in the previous literature $[2,4,6,13,16,17,20,21]$. Given that organizational goals under each ownership type affect the way resources are allocated and acquired from audiences (e.g., publics, government, and clients) [27], we expect the effect of the determinants of hospital profitability to vary with these various ownership types.

\subsection{Variable Definition}

To examine the association between the operating factors and profitability varying with ownership type, we first need to examine the effect of the individual operating factors on profitability. Following prior literature, we handpicked 10 determinants of hospital profitability: DT, NP, UC, DR, DC, TL, MCAI, MCAR, CTO, and BH. DT is a hospital type dummy that takes the value of 0,1 , or 2 if the hospital is proprietary, voluntary nonprofit, or governmental, respectively. NP is the number of patients; UC is the uncompensated costs. DR is a resident program dummy, which takes the value of 1 if the hospital has a residency program and 0 otherwise. DC is a hospital chain dummy, which takes the value of 1 if the hospital is affiliated with a multi-hospital system and 0 otherwise. TL is the total liability incurred by a hospital; MCAI is defined as the number of patients covered by Medicaid; MCAR is the number of patients covered by Medicare; CTO is the total monetary cost of the hospital; $\mathrm{BH}$ is the total bed size. The foregoing and subsequent notation is explained in the glossary. Being drawn from the prior literature, these determinants are expected to have statistically significant power in explaining hospital profitability. Our ex ante expectations for the signs of the coefficients are as follows.

\subsection{Ex Ante Expectation and Hypotheses Development}

\subsubsection{Ownership Type (DT)}

Unlike government and nonprofit hospitals, for-profit hospitals are expected to distribute profits to shareholders and are the most profit-oriented of the three types. For-profit hospitals have been found to likely provide profitable medical services, whereas government hospitals likely provide unprofitable medical services [30]. For-profit hospitals also tend to be more sensitive than government and nonprofit hospitals to changes in service profitability [30]. Previous studies find higher profitability among for-profit hospitals than among other types of hospitals because the profit incentive drives more efficient operations $[2,4,6,17,21]$.

Our ex ante expectation of the relation of ownership type to hospital profitability is negative and statistically significant. The negative relationship implies that for-profit hospitals $(\mathrm{DT}=0)$ are expected 
to generate a higher profit than non-profit hospitals $(\mathrm{DT}=1)$, and non-profit hospitals are expected to generate a higher profit than government hospitals $(\mathrm{DT}=2)$.

\subsubsection{Number of Patients (NP)}

A large patient volume may generally increase profitability, but the effect would vary with the type of patient such as the payer group and severity of illness [31]. For instance, it is well known that higher payments are made by the privately insured than the publicly insured. Additionally, patient severity increases costs, as more intensive treatment is made to severely ill patients. Without information about the patient characteristics, we refrain from a definitive prediction regarding the main effect of the number of patients.

\subsubsection{Uncompensated Costs (UC)}

Uncompensated care costs are incurred when patients who are indigent or lack insurance cannot pay for the medical services delivered (e.g., emergency room visits). High levels of uncompensated costs, which would have been paid if the patients were insured, can generate a huge financial strain for hospitals and decrease the hospital profitability [6]. Additionally, previous researchers have found that uncompensated care reduces the overall output of hospitals [32]. Our ex ante expectation of the relation of uncompensated costs to hospital profitability is thus negative and statistically significant.

\subsubsection{Teaching Status (DR)}

Teaching status is measured as whether a hospital has a residency program (i.e., offers training for the next generation of physicians). To support their educational mission, teaching hospitals have access to funding from various sources to which non-teaching hospitals do not [6]. Teaching hospitals are also reputed to command higher prices because the affiliation with a medical school enhances their reputation. However, teaching programs are costly [7,33]. Previous literature has suggested that the cost of supporting such programs exceeds the generated revenue, decreasing the profitability [6]. Hence, our ex ante expectation of the relation of teaching program to hospital profitability is negative and statistically significant.

\subsubsection{Hospital Chain (DC)}

System affiliation enables member hospitals to command higher reimbursement rates and achieve economies of scale [6,34]. Additionally, it is expected to allow these types of hospitals, compared to independent hospitals, to better coordinate various activities in the area of financial and human resource management, cost control, etc. [35]. These advantages are expected to increase profitability $[4,21]$. Thus, our ex ante expectation of the relation of hospital chain to hospital profitability is positive and statistically significant.

\subsubsection{Total Liability (TL)}

Liability (debt) is expected to be negatively associated with profitability because it incurs interest costs and the risk of becoming insolvent [6]. Additionally, when hospitals are largely leveraged, several restrictions (e.g., maintenance of the current level of leverage, or no additional debt until their debt are paid) can be imposed by debt holders. This can potentially prevent hospitals from borrowing more funds or pursuing various activities that might help increase profitability. Our ex ante expectation of the relation of total liability to hospital profitability is thus negative and statistically significant.

\subsubsection{Medicaid Patients (MCAI)}

Because the Medicaid program provides health coverage for those of all ages with insufficient income to pay for their health care, the number of Medicaid patients is expected to have a negative association with profitability. This association is due to the low reimbursement rates for Medicaid 
patients (lower than for Medicare patients) and the more expensive treatment for Medicaid patients because they "have a worse health status, experience more complications, and use more resources than privately insured patients" (p. 746) [36]. Thus, we expect the relation of Medicaid patients to hospital profitability to be negative and statistically significant.

\subsubsection{Medicare Patients (MCAR)}

Medicare, which is the federal insurance program that provides coverage for people who are 65 and older, reimburses hospitals at much lower rates than private insurance plans. One good example can be found in emergency departments. While Medicare use a fixed-fee based system for reimbursing inpatient hospitalizations and outpatient emergency department visits, private insurers use various ways of reimbursement including a per diem basis, providing higher profits for hospitals than Medicare [37]. Given that those visiting emergency department are severely ill and thus much costly to treat, having many Medicare patients in emergency department will generate high costs, negatively affecting profitability even more. Our ex ante expectation of the relation of Medicare patients to hospital profitability is thus negative and statistically significant [6].

\subsubsection{Total Hospital Cost (CTO)}

Prior research has not investigated, to the best of our knowledge, how total hospital cost affects hospital profitability. Cost containment has long been a major interest of policy makers and hospital administrators. Costs, however, are often inevitable in creating new revenue stream. For example, investment in new equipment might increase costs at first but eventually increase market share and patient volume. Additionally, reducing costs consequent to reductions in numbers of tests or length of stay might negatively affect quality of care and thereby decrease overall hospital profitability. That said, our ex ante expectation of the relation of total hospital cost to hospital profitability is positive and statistically significant.

\subsubsection{Bed Size (BH)}

The bed size, which is a proxy for the hospital size, is expected to be positively associated with profitability because of the economies of scale $[7,20]$. While large hospitals can share the fixed infrastructural and administrative costs across the units and thus reduce average costs, small hospitals are often too small to do so. Our ex ante expectation of the bed size to hospital profitability is thus positive and statistically significant.

As mentioned above, we expect that the effects of these variables vary with different types of hospitals. Our second hypothesis can thus be stated as follows.

Hypothesis 1 (H1). The sensitivity of the hospital profitability with respect to the nine variables is identical;

Hypothesis 2 (H2). The sensitivity of hospital profitability with respect to the nine variables varies with different type of hospital.

\section{The Model}

\subsection{Determinants of Hospital Profitability}

The variable MRG, which is defined as the margin, represents hospital profitability.

$$
\text { Model 1: } M R G_{i}=\alpha+\beta X_{i}+\epsilon_{i}
$$

where $X_{i}=\left(D T_{i}, N P_{i}, U C_{i}, D R_{i}, D C_{i}, T L_{i}, M C A I_{i}, M C A R_{i}, C T O_{i}, B H_{i}\right)^{T}$, and $\beta=$ $\left(\beta_{1}, \beta_{2}, \beta_{3}, \beta_{4}, \beta_{5}, \beta_{6}, \beta_{7}, \beta_{8}, \beta_{9}, \beta_{10}\right)^{T}$. 


\subsection{Effect of Hospital Ownership Type}

We created three mutually exclusive and exhaustive subsamples for proprietary (i.e., for-profit), nonprofit, or governmental and assign these groups the numbers 1, 2, and 3, respectively. The proprietary group with $g=1$ includes all hospitals with $\mathrm{DT}=0$. The voluntary nonprofit group with $g=2$ includes all hospitals with DT $=1$. The governmental group with $g=3$ includes all hospitals with $\mathrm{DT}=2$. We identified three subgroups by adding a subscript $\mathrm{g}$ to Model 1 and derive Model 2 as follows.

$$
\text { Model 2: } M R G_{i, g}=\alpha_{g}+\beta_{g} X_{i, g}^{\prime}+\epsilon_{i, g}
$$

where $X_{i, g}^{\prime}=\left(N P_{i, g}, U C_{i, g}, D R_{i, g}, D C_{i, g}, T L_{i, g}, M C A I_{i, g}, M C A R_{i, g}, C T O_{i, g}, B H_{i, g}\right)^{T}$, and $\beta_{i, g}=$ $\left(\beta_{1, i, g}, \beta_{2, i, g}, \beta_{3, i, g}, \beta_{4, i, g}, \beta_{5, i, g}, \beta_{6, i, g}, \beta_{7, i, g}, \beta_{8, i, g}, \beta_{9, i, g}\right)^{T}$.

We analyzed whether the factors that explain hospital profitability vary with the hospital type by estimating Model 2 for each group. This analysis enabled us to test our previously discussed hypothesis by comparing the estimated coefficients. Based on Model 2, our hypothesis can be restated as follows.

$\mathrm{H} 1: \beta_{1}=\beta_{2}=\beta_{3}$

$\mathrm{H} 2$ : Otherwise

\section{Empirical Results}

\subsection{Data}

Our model draws data from the hospital cost reports available from the Center for Medicare and Medicaid Services (CMS). CMS requires all Medicare reimbursable facilities to annually submit a cost report (downloadable from www.cms.gov). Our sample includes 55,163 hospital-year observations from 1997 to 2010. Table 1 shows the summary statistics of the full sample. We find that some variables (operating profit, NP, UC, and TL) show very large kurtosis and we note that these variables may not be normally distributed.

Table 1. Descriptive statistics.

\begin{tabular}{cccccccccccc}
\hline & Operating Profit & DT & NP & UC & DR & DC & TL & MCAI & MCAR & CTO & BH \\
\hline Mean & 56.39 & 1.017 & 182 & 0.044 & 0.207 & 0.192 & 943 & 0.119 & 0.505 & 85.337 & 1.350 \\
Stdev & 532.88 & 0.672 & 192 & 0.525 & 0.406 & 0.394 & 134263 & 0.113 & 0.195 & 145.064 & 1.519 \\
Skewness & -116 & -0.020 & 108 & 111 & 1.443 & 1.560 & 162 & 2.034 & -0.312 & 5.362 & 2.832 \\
Kurtosis & 21604 & -0.789 & 15568 & 16658 & 0.081 & 0.435 & 27943 & 6.484 & -0.126 & 52.076 & 13.685 \\
\hline
\end{tabular}

Notes: The dependent variable is operating profit (in millions). DT is a hospital type dummy variable, which takes the value of 0,1 , or 2 if the hospital is proprietary, voluntary nonprofit, or governmental, respectively. NP is the number of patients; UC is the uncompensated costs (in millions); DR is a resident program dummy, which takes the value of 1 if the hospital has a residency program and 0 otherwise. DC is a hospital chain dummy, which takes the value of 1 if the hospital is affiliated with a multihospital system and 0 otherwise. TL is the total liability that a hospital incurs; MCAI is the number of patients covered by Medicaid; MCAR is the number of patients covered by Medicare; CTO is the total monetary cost of the hospital (in millions); $\mathrm{BH}$ is the total bed size (in $100 \mathrm{~s}$ ). The pooled sample contains 55,163 observations made during 1997-2010.

\subsection{Empirical Result}

We use ordinary least squares (OLS) regression models to estimate our coefficients with heteroskedasticity-consistent standard errors. Table 2 summarizes the results of Model 1.

Table 2. Estimated results of Model 1.

\begin{tabular}{cccc}
\hline & Coef. & $\mathbf{t}$ & $p$-Value \\
\hline DT & -12.61 & -3.590 & 0.000 \\
NP & 0.04 & 2.030 & 0.232 \\
\hline
\end{tabular}


Table 2. Cont.

\begin{tabular}{cccc}
\hline & Coef. & $\mathbf{t}$ & $\boldsymbol{p}$-Value \\
\hline UC & -22.48 & -4.970 & 0.132 \\
DR & 3.52 & 0.520 & 0.825 \\
DC & 4.61 & 0.770 & 0.529 \\
TL & 0.00 & -0.590 & 0.305 \\
MCAI & -56.27 & -2.510 & 0.002 \\
MCAR & -11.52 & -0.800 & 0.330 \\
CTO & 0.57 & 19.330 & 0.001 \\
BH & 9.93 & 3.450 & 0.063 \\
Constant & 16.88 & 1.500 & 0.091 \\
Number of obs & 55163 & & \\
Adj R-squared & 0.0347 & & \\
\hline
\end{tabular}

Notes: This table presents the estimated results of Model 1. The dependent variable is the operating profit (in millions). DT is a hospital type dummy variable, which takes the value of 0,1 , or 2 if the hospital is proprietary, voluntary nonprofit, or governmental, respectively. NP is the number of patients; UC is the uncompensated costs (in millions); DR is a resident program dummy, which takes the value of 1 if the hospital has a residency program and 0 otherwise. DC is a hospital chain dummy, which takes the value of 1 if the hospital is affiliated with a multihospital system and 0 otherwise. TL is the total liability that a hospital incurs; MCAI is the number of patients covered by Medicaid; MCAR is the number of patients covered by Medicare; CTO is the total monetary cost of the hospital (in millions); $\mathrm{BH}$ is the total bed size (in $100 \mathrm{~s}$ ). The pooled sample contains 55,093 observations made during 1997-2010. The authors initially wanted to make time-consistent matching for hospitals but found that there were number of hospitals that had changed their ownership structure over time. Employing standard panel estimators can ignore such time-varying conditions, so the authors felt that the best way to overcome this problem was to treat hospitals independently over time. The fixed effect model, however, was performed to see if there were lasting (unaltered) resources that may leave hospital behavior unchanged even if the ownership structure changes. The results show that there is no fixed effect, providing empirical evidence that ownership structure change is indeed the major driver for hospital profitability persuasion.

Note that the reported $t$-stat and $p$-value are based on heteroskedasticity-consistent standard errors. The results in Table 2 indicate that ownership type greatly affects operating profit. The coefficient of the ownership type is negative and significant. The coefficient of the number of patients is positive but insignificant, which suggests that hospital profitability does not necessarily increase with the number of patients. Contrary to our predictions, the coefficients of the uncompensated costs, teaching status, hospital chain, and total liability are insignificant. The coefficient of the number of patients covered by Medicaid is negative and significant, but the coefficient of the number of patients covered by Medicare is insignificant. The coefficient of the total hospital costs is positive and significant, which suggests that the hospital profitability does not decrease but increases with increasing cost. The coefficient of the bed size is positive but not statistically significant; nonetheless, the positive correlation of the bed size with the operating profit suggests economies of scale.

The estimated coefficients of the variables DT, MCAI, and CTO, are consistent with our stated ex ante expectations, not interesting and hence not discussed further. However, the estimated coefficients of the variables $\mathrm{UC}, \mathrm{DR}, \mathrm{DC}, \mathrm{TL}, \mathrm{MCAR}$, and $\mathrm{BH}$ are contrary to our ex ante expectations and hence warrant discussion.

The insignificant result of the variable UC may suggest that hospitals under pressure are successful in compensating for losses, e.g., by finding various sources of funding or ordering excessive procedures and tests. The results in Table 2, which shows that the variable DR does not have a statistically significant effect on profitability, may reflect the mixed results in the previous literature [13,17]. One possibility is that the cost-increasing effect of the teaching programs [17] is offset by the revenue-enhancing effect of the teaching status [13]. The variable DC, which is expected to positively affect hospital profitability, is shown to not have a significant effect based on empirical investigation. There are a couple of possible explanations for this result. If hospitals that can benefit from joining a chain are already part of the system, no effect on profitability is likely observed [6]. Alternatively, affiliation may cause the hospitals to inefficiently allocate capital, staffing, and other resource across units, which weakens the positive effect of the system affiliation on profitability. The coefficient of TL is negative as expected but not statistically 
significant. Instead of having a negative effect, the hospitals' obligations to finance operations and pay for large expansions can increase the overall quality of service and attract more patients. The variable MCAR has the expected negative effect on hospital profitability, but it is not statistically significant. The consideration of whether hospitals can compensate for the losses that are incurred by treating many Medicare patients may inform our understanding of the observed relationship. The negative effect of Medicare patients can be offset, for example, if a hospital can attract many privately insured patients. The insignificant result of the variable $\mathrm{BH}$ shows that there can be some groups of hospitals that fail to achieve economies of scale. In addition, the absence of statistical significance in many of the results in Model 1 could imply that other variables not considered in our study may influence the profitability, or that the variables included were measured incorrectly.

Without further empirical investigation, however, the arguments for why the empirical estimation is inconsistent with our ex ante expectation would be mere speculation. Therefore, we propose further investigating the relationship between the variables and the hospital profitability holds in the sub-sample, but not for the full sample. We specifically divided the sample into categories based on ownership type, which sets distinctive organizational goals that are transformed into preferences and guidelines in choosing among alternative sets of action. We believe doing so may yield insights into actual relations in the sample.

\subsection{Effect of Hospital Type}

Table 3 reports the results of Model 2. The parameter estimates for the for-profit, nonprofit, and government hospitals are reported below.

Table 3. Estimated results of Model 2.

\begin{tabular}{cccc}
\hline & $\mathbf{d}=\mathbf{0}$ & $\mathbf{d}=\mathbf{1}$ & $\mathbf{d = 2}$ \\
\hline NP & 0.19 & 0.02 & 0.04 \\
& $(0.00)$ & $(0.53)$ & $(0.13)$ \\
UC & -38.48 & -17.77 & -21.02 \\
& $(0.15)$ & $(0.79)$ & $(0.14)$ \\
DR & -22.17 & 18.70 & -41.00 \\
& $(0.03)$ & $(0.36)$ & $(0.01)$ \\
DC & -9.88 & 9.90 & -15.91 \\
& $(0.01)$ & $(0.47)$ & $(0.39)$ \\
TL & 0.00 & 0.00 & -0.27 \\
& $(0.11)$ & $(0.35)$ & $(0.18)$ \\
MCAI & -73.64 & -34.43 & -60.08 \\
& $(0.00)$ & $(0.09)$ & $(0.04)$ \\
MCAR & -27.28 & -34.90 & 61.04 \\
& $(0.00)$ & $(0.09)$ & $(0.00)$ \\
CTO & 1.09 & 0.63 & 0.46 \\
& $(0.00)$ & $(0.01)$ & $(0.00)$ \\
BH & 13.75 & -1.34 & 24.93 \\
& $(0.02)$ & $(0.86)$ & $(0.01)$ \\
Constant & -19.87 & 21.37 & -46.49 \\
& $(0.02)$ & $(0.22)$ & $(0.00)$ \\
Number of obs & 12075 & 30355 & 12733 \\
Adj R-squared & 0.1298 & 0.0265 & 0.1087 \\
\hline
\end{tabular}

Notes: This table presents the estimated results of Model 2. The dependent variable is the operating profit (in millions). DT is a hospital type dummy variable, which takes the value of 0,1 , or 2 if the hospital is proprietary, voluntary nonprofit, or governmental, respectively. NP is the number of patients; UC is the uncompensated costs (in millions); DR is a resident program dummy, which takes the value of 1 if the hospital has a residency program and 0 otherwise. DC is a hospital chain dummy, which takes the value of 1 if the hospital is affiliated with a multihospital system and 0 otherwise. TL is the total liability that a hospital incurs; MCAI is the number of patients covered by Medicaid; MCAR is the number of patients covered by Medicare; CTO is the total monetary cost of the hospital (in millions); $\mathrm{BH}$ is the total bed size (in $100 \mathrm{~s}$ ). $p$-Values are included in the parentheses. The pooled sample contains 55,163 observations made during 1997-2010. 
The coefficient of the number of patients is positive and significant only for for-profit hospitals. This suggests that greater profitability does not necessarily result from treating more patients. What we can infer, however, is that the patient characteristics differ across ownership type. As the proportion of privately insured patients is much greater for for-profit hospitals due to its profit-maximization goal, treating additional patients may increase the profitability for for-profit hospitals compared to other types. Nonprofit and government hospitals are not expected to benefit from treating more patients with low reimbursement rates.

As in the full sample (Table 2), the effect of uncompensated costs is not statistically significant for for-profit, nonprofit, and government hospitals. Hospitals with high levels of uncompensated costs are under pressure to compensate the losses. One might argue that all types of hospitals successfully compensate the losses, but without the more detailed information, we only infer that uncompensated costs do not affect profitability in all three types.

The coefficient of the teaching status is insignificant in Table 2. When we analyze the effect for individual groups, however, we find that the coefficient of the teaching status is negative and significant for for-profit and government, being consistent with our previously stated ex ante expectations. Further, we found that the coefficient of the teaching status is positive but insignificant for nonprofit hospitals. This was the reason why teaching status has a result contrary to our ex ante expectations in the full sample. This result in Table 2 appears to suggest that affiliation with a medical school does not enhance reputation or thus performance as strongly for for-profit and government hospitals as it does for nonprofit hospitals [8]. Because the reputation is important in raising funds from donors or corporate partners, a residency program is beneficial for nonprofits and helps offset the large cost of sponsorship.

The coefficient of the hospital chain is insignificant in Table 2 but negative and significant for for-profit hospitals in Table 3, which contradicts our prediction. This result suggests that system affiliation does not always provide benefits such as high reimbursement rates, economies of scale, and increases in profit [2,6]. In particular, our result suggests that for-profit hospitals, which are under pressure to maximize profits, may experience reduced profitability. This might be due to the loss of their local decision-making power to a headquarter that may shift resources to other partner firms in the system.

Similar to Table 2, the coefficients of the total liability are insignificant for all three ownership types, which suggests that hospitals that aggressively borrow to invest in new equipment or technology or pursue acquisitions do not always incur losses consequent to the high interest rates. Thus, liability itself does not necessarily impair the hospital profitability.

The Medicaid and Medicare coefficients are insignificant for nonprofit hospitals but not for other types of hospitals. The coefficients of Medicaid are negative and significant for for-profit and government hospitals, as previously theorized. The combination of the very low reimbursement rates and poor health status for Medicaid patients negatively affects profitability of both for-profit and government hospitals. Table 3 shows that the coefficients of Medicare are negative and significant for for-profit hospitals and positive and significant for government hospitals. The low reimbursement rates for treating Medicare patients do not compensate the costs incurred by for-profit hospitals, which reduces profitability. Government hospitals, on the other hand, are not as negatively affected by the low reimbursement rates for Medicare patients. This could be because government hospitals receive large amount of tax subsidization for acting as providers of last resort and filling the unmet needs of medical services. Unfortunately, the insignificant results for nonprofit hospitals, who occupy the middle ground between for-profit and government hospitals, are not well explained.

The coefficients of the total hospital cost are positive and significant for all three types of hospitals, being consistent with our stated ex ante expectations. This result suggests that increasing cost does not necessarily have a negative effect. Increased costs can be used in improving quality of care and attracting more patients, which thereby increases the hospital profitability. 
A positive effect of the bed size on profitability is observed for only for-profit and government hospitals but not for nonprofit hospitals. Because $60 \%$ of the hospitals are nonprofits, we speculate that there is considerable variation in hospital size among nonprofits, some of which are experiencing diseconomies of scale [14].

We believe that the dummy variable we employed is very unlikely to suffer from endogeneity problem of simultaneity in ownership dummy and other independent variables. The ownership structure of a hospital is, however, determined externally. For example, a hospital does not become government-owned because of its large bed size. A hospital also does not become non-profit organization because it takes Medicare patients. Therefore, we do not believe such endogeneity of the dummy we employed would critically affect the result of our analysis.

The only possibility of endogeneity is that some hidden factors could affect the independent variables simultaneously. These examples could be population structure or income of a county. We agree that these factors could potentially cause endogeneity problem. However, to our knowledge, no previous research has investigated such factors, so it is practically difficult to pursue such investigation on our own, as this is not within the scope of our main research objectives.

\subsection{Multicollinearity Test}

To ensure that our models do not suffer from multicollinearity, we conducted the variance inflation factor (VIF) test as shown in Table 4. The VIF test quantifies the degree of increase in variance (the square of the estimate's standard deviation) of an estimated coefficient because of collinearity. The estimated variance of the estimated OLS coefficient is expressed as

$$
\operatorname{vâr}\left(\hat{\beta}_{j}\right)=\frac{s^{2}}{(n-1) \operatorname{var} r\left(X_{j}\right)} \cdot \frac{1}{1-R_{j}^{2}}
$$

where $X_{j}$ is the value of the jth independent variable, $\hat{\beta}_{j}$ is the estimated coefficient of the independent variable , and $R_{j}^{2}$ is the multiple for the regression of on the other independent variables.

There may be a concern of missing unknown unknowns. However, based on the result of the VIF, we argue that such an effect should not cause any major specification problem because our models are econometrically well specified for the following reasons: (1) We employed factors that have been proven to have statistically significant explanatory power from previous literature; (2) we investigated the variance inflation factor to find that there is no evidence of multicollinearity; (3) we employed cross-sectional data so that the model could not suffer from serial correlation; and (4) we employed heteroskedasticity-consistent standard errors. 
Table 4. Multicollinearity test.

\begin{tabular}{|c|c|c|c|c|c|c|c|c|c|c|c|}
\hline \multicolumn{3}{|c|}{ Panel A: Model 1} & \multicolumn{3}{|c|}{ Panel B: $d=0$} & \multicolumn{3}{|c|}{ Panel C: $\mathrm{d}=1$} & \multicolumn{3}{|c|}{ Panel D: $d=2$} \\
\hline & Coef. & Variable & Variable & VIF & 1/VIF & Variable & VIF & 1/VIF & Variable & VIF & 1/VIF \\
\hline DT & 3.88 & $\mathrm{BH}$ & $\mathrm{BH}$ & 3.9 & 0.256094 & $\mathrm{BH}$ & 4.06 & 0.246193 & $\mathrm{BH}$ & 3.9 & 0.256094 \\
\hline $\mathrm{NP}$ & 3.72 & CTO & СТO & 3.76 & 0.266015 & CTO & 3.94 & 0.253628 & CTO & 3.76 & 0.266015 \\
\hline UC & 1.52 & MCAR & $\mathrm{dr}$ & 1.82 & 0.549698 & MCAR & 1.57 & 0.63746 & $\mathrm{dr}$ & 1.82 & 0.549698 \\
\hline $\mathrm{DR}$ & 1.51 & DR & mcar & 1.76 & 0.56971 & DR & 1.51 & 0.663794 & mcar & 1.76 & 0.56971 \\
\hline DC & 1.29 & MCAI & mcai & 1.43 & 0.698995 & MCAI & 1.3 & 0.768702 & mcai & 1.43 & 0.698995 \\
\hline TL & 1.14 & UC & $\mathrm{np}$ & 1.37 & 0.732223 & UC & 1.11 & 0.903609 & np & 1.37 & 0.732223 \\
\hline MCAL & 1.13 & NP & $\mathrm{dc}$ & 1.03 & 0.966592 & NP & 1.11 & 0.903948 & $\mathrm{dc}$ & 1.03 & 0.966592 \\
\hline MCAR & 1.12 & DC & uc_r & 1.02 & 0.984514 & DC & 1.06 & 0.94625 & uc_r & 1.02 & 0.984514 \\
\hline CTO & 1.01 & $\mathrm{TL}$ & $\mathrm{tl}$ & 1 & 0.999142 & $\mathrm{TL}$ & 1 & 0.999824 & $\mathrm{tl}$ & 1 & 0.999142 \\
\hline $\mathrm{BH}$ & 1.00 & & & & & & & & & & \\
\hline Mean VIF & 1.73 & & Mean VIF & 1.78 & & Mean VIF & 1.85 & & Mean VIF & 1.9 & \\
\hline
\end{tabular}

Notes: This table presents the estimated results of variance inflation factor (VIF) test for Model 1, in Panel A, and Model 2, in Panels B, C, and D. The dependent variable is the operating profit (in millions). DT is a hospital type dummy variable, which takes the value of 0,1 , or 2 if the hospital is proprietary, voluntary nonprofit, or governmental, respectively. NP is the number of patients; UC is the uncompensated costs (in millions); DR is a resident program dummy, which takes the value of 1 if the hospital has a residency program and 0 otherwise. DC is a hospital chain dummy, which takes the value of 1 if the hospital is affiliated with a multihospital system and 0 otherwise. TL is the total liability that a hospital incurs; MCAI is the number of patients covered by Medicaid; MCAR is the number of patients covered by Medicare; CTO is the total monetary cost of the hospital (in millions); BH is the total bed size (in 100 s). The pooled sample contains 55,163 observations made during 1997-2010. 


\section{Conclusions}

In this paper, we have examined various factors associated with hospital profitability using the data from hospital cost reports available from the CMS. While we theorize 10 determinants of hospital profitability based on previous literature, we find that only 3 out of 10 estimated coefficients are consistent with our prediction. Holding that the inconsistent results arise from the difference in hospital ownership, we conduct additional analysis by dividing the sample hospitals into three sub-groups: for-profit, nonprofit, and government.

Our analysis with three types of hospitals helps us to elucidate the effect of each determinant on profitability. Overall, the results in the sub-sample analysis suggest that each determinant has a varying effect on profitability depending on ownership type. This implies that the effort of hospital administrators who seek to increase profitability should be guided by the ownership type to particular aspects of operation.

The results for nonprofit hospitals that lack a clear objective function for management remain puzzling though. Many coefficients for nonprofit hospitals are inconsistent to the ex ante expectation as they have too many stakeholders such as their members, directors, or constituencies that exercise control over the management of the hospital. In future studies, researchers can benefit further from studies investigating the different types of nonprofit hospitals that might vary with their objectives. For instance, future studies can compare the effects of the determinants of profitability for church-owned nonprofit hospitals vs. their secular nonprofit counterparts, as religious nonprofit hospitals are more likely to be patient-centered and emphasize charity care than non-religious nonprofit hospitals. It would be interesting to see whether religious nonprofit hospitals act more like government hospitals, while non-religious nonprofit hospitals act like for-profit hospitals.

To our knowledge, this is the first attempt to construct such a model, so we consider this as our first contribution. The second contribution of the paper is to find that the objective function of a hospital varies depending on the type of the hospital.

Taken together, this paper enhances our understanding of factors associated with hospital profitability, which ultimately affects the sustainability in the healthcare system. Especially, nonprofit hospitals without a clear objective perform differently from the other two types that have relatively clearer objectives. Hospital administrators should, depending on ownership type, differentially formulate their strategies to increase their profitability.

Acknowledgments: For Na-Eun Cho, this research was supported by the Hongik University Research Fund. For KiHoon Hong, this research was supported by the Basic Science Research Program through the National Research Foundation of Korea (NRF) funded by the Ministry of Education (NRF-2016R1D1A1B03930195).

Author Contributions: Na-Eun Cho provided hospital data and expertise on hospital structure and profitability; Kihoon Hong conducted empirical tests and interpreted their implications; Na-Eun Cho and Kihoon Hong contributed to the model results and wrote the paper.

Conflicts of Interest: The authors declare no conflict of interest.

$\begin{array}{ll}\text { Abbreviation } \\ \text { MRG } & \text { operating profit margin } \\ \text { DT } & \text { hospital type dummy } \\ \text { NP } & \text { number of patients } \\ \text { UC } & \text { uncompensated costs } \\ \text { DR } & \text { residence dummy variable } \\ \text { DC } & \text { hospital chain dummy variable } \\ \text { TL } & \text { total liability } \\ \text { MCAI } & \text { number of patients covered by Medicaid } \\ \text { MCAR } & \text { number of patients covered by Medicare } \\ \text { CTO } & \text { total hospital cost } \\ \text { BH } & \text { total bed size }\end{array}$




\section{References}

1. Sloan, F.A.; Vraciu, R.A. Investor-owned and not-for-profit hospitals: Addressing some issues. Health Aff. 1983, 2, 25-37. [CrossRef]

2. Renn, S.C.; Schramm, C.J.; Watt, J.M.; Derzon, R.A. The effects of ownership and system affiliation on the economic performance of hospitals. Inquiry 1985, 22, 219-236. [PubMed]

3. Valvona, J.; Sloan, F.A. Hospital profitability and capital structure: A comparative analysis. Health Serv. Res. 1988, 23, 343-357. [PubMed]

4. Lynch, J.R.; McCue, M.J. The effects of for-profit multihospital system ownership on hospital financial and operating performance. Health Serv. Manag. Res. 1990, 3, 182-192. [CrossRef] [PubMed]

5. Sear, A.M. Comparison of efficiency and profitability of investor-owned multihospital systems with not-for-profit hospitals. Health Care Manag. Rev. 1991, 16, 31-37. [CrossRef]

6. Gapenski, L.G.; Vogel, W.B.; Langland-Orban, B. Determinants of hospital profitability. Hosp. Health Serv. Adm. 1993, 38, 63-80. [PubMed]

7. Vogel, W.B.; Langland-Orban, B.; Gapenski, L.C. Factors influencing high and low profitability among hospitals. Health Care Manag. Rev. 1993, 18, 15-26. [CrossRef]

8. Walker, C.L. A cross-sectional analysis of hospital profitability. J. Hosp. Mark. 1993, 7, 121-138. [CrossRef] [PubMed]

9. Langland-Orban, B.; Gapenski, L.C.; Vogel, W.B. Differences in characteristics of hospitals with sustained high and sustained low profitability. J. Healthc. Manag. 1996, 41, 385-399.

10. Zeller, T.L.; Stanko, B.B.; Cleverley, W.O. A new perspective on hospital financial ratio analysis. Healthc. Financ. Manag. 1997, 51, 62-67.

11. Chang, H.H. Determinants of hospital efficiency: The case of central government-owned hospitals in Taiwan. Omega 1998, 26, 307-317. [CrossRef]

12. Harris, J., II; Ozgen, H.; Ozcan, Y. Do mergers enhance performance of hospital efficiency? J. Oper. Res. Soc. 2000, 51, 801-811. [CrossRef]

13. Younis, M.; Rice, J.; Barkoulas, J. An empirical investigation of hospital profitability in the post-PPS era. J. Healthc. Financ. 2001, 28, 65-73.

14. Kim, Y.K.; Glover, S.H.; Stoskopf, C.H.; Boyd, S.D. The relationship between bed size and profitability in South Carolina hospitals. J. Healthc. Financ. 2002, 29, 53-63.

15. Watcharasriroj, B.; Tang, J.C. The effects of size and information technology on hospital efficiency. J. High Technol. Manag. Res. 2004, 15, 1-16. [CrossRef]

16. Younis, M.; Forgione, D. Using return on equity and total profit margin to evaluate hospital performance in the US: A piecewise regression analysis. J. Healthc. Financ. 2005, 31, 82-88.

17. Younis, M.; Younies, H.; Okojie, F. Hospital financial performance in the United States of America: A follow-up study. East. Mediterr. Health J. 2006, 12, 670-678. [PubMed]

18. Shen, Y.C.; Eggleston, K.; Lau, J.; Schimid, C.H. Hospital ownership and financial performance: What explains the different findings in the empirical literature? Inquiry 2007, 44, 41-68. [CrossRef] [PubMed]

19. Rauscher, S.; Wheeler, J.R. The importance of working capital management for hospital profitability: Evidence from bond-issuing, not-for-profit US hospitals. Health Care Manag. Rev. 2012, 37, 339-346. [CrossRef] [PubMed]

20. Langland-Orban, B.; Large, J.T.; Sear, A.M.; Zhang, H.; Zhang, N. Operating profitability of for-profit and not-for-profit Florida community hospitals during Medicare policy changes, 2000 to 2010. Inquiry 2015, 52, 1-7. [CrossRef] [PubMed]

21. Bai, G.; Anderson, G.F. A more detailed understanding of factors associated with hospital profitability. Health Aff. 2016, 35, 889-897. [CrossRef] [PubMed]

22. Hansmann, H. The Ownership of Enterprise; Harvard University Press: Cambridge, MA, USA, 1996.

23. Sloan, F.A. Not-for-profit ownership and hospital behavior. In Handbook of Health Economics; Newhouse, J.P., Culyer, A., Eds.; Elsevier: Amsterdam, The Netherlands, 1998.

24. Jensen, M.C.; Meckling, W.H. Theory of the firm: Managerial behavior, agency costs and ownership structure. J. Financ. Econ. 1976, 3, 305-360. [CrossRef]

25. Fama, E.F.; Jensen, M.C. Separation of ownership and control. J. Law Econ. 1983, 26, 301-325. [CrossRef]

26. Simon, H.A. On the concept of organizational goal. Admin. Sci. Q. 1964, 9, 1-22. [CrossRef] 
27. Scott, W.R.; Davis, G.F. Organizations and Organizing: Rational, Natural, and Open Systems; Pearson Education: Upper Saddle River, NJ, USA, 2007.

28. Peabody, R.L.; Rourke, F.E. Public bureaucracies. In Handbook of Organizations; March, J.G., Ed.; Rand McNally \& Company: Chicago, IL, USA, 1965; pp. 802-837.

29. Perry, J.L.; Rainey, H.G. The public-private distinction in organization theory: A critique and research strategy. Acad. Manag. Rev. 1988, 13, 182-201.

30. Horwitz, J.R. Making profits and providing care: Comparing nonprofit, for-profit and government hospitals. Health Aff. 2005, 24, 790-801. [CrossRef] [PubMed]

31. Friedman, B.; Sood, N.; Engstrom, K.; McKenzie, D. New evidence on hospital profitability by payer group and the effects of payer generosity. Int. J. Health Financ. Econ. 2004, 4, 231-246. [CrossRef] [PubMed]

32. Ferrier, G.D.; Rosko, M.D.; Valdmanis, V.G. Analysis of uncompensated hospital care using a DEA model of output congestion. Health Care Manag. Sci. 2006, 9, 181-188. [CrossRef] [PubMed]

33. Koenig, L.; Dobson, A.; Ho, S.; Siegel, J.M.; Blumenthal, D.; Weissman, J.S. Estimating the mission-related costs of teaching hospitals. Health Aff. 2003, 22, 112-122. [CrossRef]

34. Lewis, M.S.; Pflum, K.E. Diagnosing hospital system bargaining power in managed care Networks. Am. Econ. J. Econ. Policy 2015, 7, 243-274. [CrossRef]

35. Levitz, G.; Brooke, P. Independent versus system-affiliated hospitals: A comparative analysis of financial performance, cost and productivity. Health Serv. Res. 1985, 20, 315-340. [PubMed]

36. Waits, S.A.; Reames, B.N.; Sheetz, K.H.; Englesbe, M.J.; Campbell, D.A.J. Anticipating the effects of Medicaid expansion on surgical care. JAMA Surg. 2014, 149, 745-747. [CrossRef] [PubMed]

37. Wilson, M.; Cutler, D. Emergency department profits are likely to continue as the Affordable Care Act expands coverage. Health Aff. 2014, 33, 792-799. [CrossRef] [PubMed]

(C) 2018 by the authors. Licensee MDPI, Basel, Switzerland. This article is an open access article distributed under the terms and conditions of the Creative Commons Attribution (CC BY) license (http:/ / creativecommons.org/licenses/by/4.0/). 